\title{
PRECEDÊNCIA DE USO NO DIREITO DE MARCAS
}

\author{
Angelo da Silva Oliveira ${ }^{1}$
}

RESUMO: O direito de precedência é alvo de constantes debates, visto que a utilização das marcas cresce exponencialmente no Brasil. Para discutir a respeito da questão, o presente artigo tem como objetivo aprofundar o entendimento do direito de precedente de forma geral para adentrar no assunto marcas. A legislação brasileira adota o sistema atributivo de direito sobre marca, no qual a lei atribui o direito sobre determinada marca para o indivíduo que fizer o primeiro protocolo na instituição pública. Esta forma de procedimento gera discordância da doutrina, visto que entende o sistema como misto, ou seja, atributivo e declaratório. Além de uma lei de propriedade de marcas, pode-se encontrar a respeito do assunto na Constituição Federal de 1988, o qual a proteção de marcas está ligada aos signos marcários criados e utilizados em determinado ramo de atividade. O direito de precedência ainda é subjetivo e obscuro em relação a quando buscar o direito de propriedade de marca, por isso existe a necessidade do preenchimento das lacunas da lei com o entendimento doutrinário e jurisprudencial a respeito do tema.

Palavras-chave: Propriedade intelectual. Marcas. Direito de precedência.

RESUME: Le droit de précédence est objet de débats constants, puisque l'utilisation des marques croît de manière exceptionnelle au Brésil. Pour discuter à propos de la question, le présent article a pour objectif d'approfondir la compréhension du droit de précédent de façon générale pour entrer dans le sujet marques. La législation brésilienne adopte le système d'attribution du droit sur la marque, dans lequel la loi attribue le droit sur une marque donnée à l'individu qui fait le premier protocole dans l'institution publique. Cette forme de procédure engendre une discordance de la doctrine, car elle considère le système comme mixte, c'est-àdire attributif et déclaratoire. En plus d'une loi de propriété de marques, on peut trouver à ce sujet dans la Constitution fédérale de 1988, laquelle la protection de marques est liée aux signes marcaires créés et utilisés dans une branche d'activité donnée. Le droit de précédence est encore subjectif et obscur par rapport à quand rechercher le droit de propriété de marque, il est donc nécessaire de combler les lacunes de la loi avec la compréhension doctrinale et jurisprudentielle sur le sujet.

Mots-clés: Propriété Intellectuelle. Marques. Droit de précédence.

I Pós-graduado em Advocacia Pública pela Faculdade EducaMais. Pós-graduando em Direito da Propriedade Intelectual pela Pontifícia Universidade Católica do Rio de Janeiro - PUC-Rio. Graduado em Direito pela Universidade Federal Rural do Rio de Janeiro. E-mail: angelo.silva.oliveira@hotmail.com. 


\section{INTRODUÇÃO}

O presente artigo tem como objetivo detalhar uma visão geral do direito de precedência no ordenamento jurídico brasileiro a partir da Lei 9279/96, sobretudo em seu artigo I29, § Iº já que este significa uma mitigação do sistema atributivo adotado no Brasil, o que, em síntese, problematiza o marco inicial do direito subjetivo marcário em função do uso de uma técnica oriunda do sistema declaratório. Em seguida faz-se uma breve exposição da natureza subjetiva constitucional do direito das marcas e a sua estreita ligação entre a proteção a determinadas atividades a fim de adquirir proteção no ordenamento jurídico. Em seguida faz-se digressão à respeito do momento oportuno para se arguir o direito de precedência, já que há lacuna legislativa a respeito, abrindo espaço doutrinário e jurisprudencial em relação aos critérios necessários para que um terceiro se oponha a um registro incompatível com o uso de um determinado signo distintivo. Ainda, faz-se um cotejo quanto a possibilidade de anulação de um direito à marca deferido a partir do direito à precedência, tendo como base a posição dos Tribunais, em especial o Superior Tribunal de Justiça e o Tribunal Regional Federal da $2^{\circ}$ Região, já que este concentra a maioria das ações referentes à Propriedade Intelectual em razão da sede do INPI ser no Rio de Janeiro. Por fim, chegando à conclusão que o direito potestativo de precedência, pela nova vertente jurisprudencial, pode ser exercido a qualquer tempo, já que se trata de uma ação anulatória sem prazo específico previsto para tal postulação.

\section{VISÃO GERAL DO DIREITO DE PRECEDÊNCIA}

O direito de precedência está previsto no art.129 da Lei 9.279/96 (Lei de Propriedade Industrial - LPI) em seu parágrafo I으․

Art. 129. A propriedade da marca adquire-se pelo registro validamente expedido, conforme as disposições desta Lei, sendo assegurado ao titular seu uso exclusivo em todo o território nacional, observado quanto às marcas coletivas e de certificação o disposto nos arts. $147 \mathrm{e}$ 148.

§ I o Toda pessoa que, de boa fé, na data da prioridade ou depósito, usava no País, há pelo menos 6 (seis) meses, marca idêntica ou semelhante, para distinguir ou certificar produto ou serviço idêntico, semelhante ou afim, terá direito de precedência ao registro. 
O respectivo instituto é exceção ao sistema atributivo de registro marcário adotado pelo Brasil. Porém, para entender melhor a questão, faz-se necessário aprofundamento maior sobre os sistemas atributivo e declaratório.

O sistema utilizado no Brasil é o sistema Atributivo. Nele, a propriedade sobre a marca se forma a partir da concessão do registro conferido por instituição pública, no caso do Brasil, o Instituto Nacional de Propriedade Intelectual. Dessa forma, a pessoa que terá direito à propriedade da Marca será a primeira a protocolar o pedido de registro do signo marcário.

No sistema apontado, o uso anterior não faz parte da equação para se conceder o registro, visando apenas o uso futuro a partir da concessão do mesmo.

Já no sistema Declaratório, o uso é a principal ferramenta para se adquirir a propriedade, sendo parte fundamental, ou total, da equação. O Estado protege legalmente o signo independe de registro, basta o titular utilizar e se ocupar do mesmo. ${ }^{2}$

Como já afirmado, o Brasil adota o sistema atributivo, como pode ser observado no art.2 - da $\mathrm{LPI}^{3}$, onde o legislador apontou que a proteção dos direitos se faz presente mediante a concessão do registro.

Todavia, podemos encontrar parte da Doutrina que discorda da definição e entende o sistema utilizado no Brasil como misto. Para Lélio Shmidt o sistema deve ser considerado misto, vez que concede a propriedade ao primeiro interessado que realizar o requerimento, porém prevê exceção para o pré-utente que pode invocar o direito de precedência e impedir o registro, se valendo de seu uso anterior como triunfo. ${ }^{4}$

De fato, se observarmos a força maior dos dois sistemas, de um lado temos o registro (sistema atributivo) e de outro seu uso comprovado (sistema declaratório). Pelo sistema atributivo, o registro deveria ser soberano, sobressaindo sobre qualquer uso anterior, uma vez que a propriedade só adviria com o registro.

${ }^{2}$ BARBOSA, Denis Borges. Direito de Precedência ao Registro de Marcas. 2005.p3.

${ }^{3}$ Art. $2^{2}$ A proteção dos direitos relativos à propriedade industrial, considerado o seu interesse social e o desenvolvimento tecnológico e econômico do País, efetua-se mediante: III - concessão de registro de marca;

${ }^{4}$ BARBOSA, Denis Borges, apud SHMITD, Lélio Denícoli, op. cit.. p. 4. 
A partir do momento que o legislador abre espaço para que o uso comprovado, há pelo menos 6 meses, de signo marcário, tenha o direito de precedência sobre registro anterior, claramente dá ao "USO" força maior do que o "PEDIDO DE REGISTRO", mesclando assim, de certa forma, os sistemas.

Nas palavras de Barbosa ${ }^{5}$ :

No CPI atual, Lei 9279/96, assim como no CPI de 1945, vigora o sistema misto, qual seja, um sistema predominantemente o sistema atributivo da propriedade marcária, isto é, a propriedade da marca se adquire somente através do seu registro no INPI, com algumas exceções como a prevista no artigo I29 parágrafo Iㅇ.

A marca invocada para se utilizar o direito de precedência não precisa ser notória ou provar sua relevância no mercado, bastando apenas existir na sociedade. Nesses moldes, se vê que a exceção não está atrelada ao conhecimento de uma determinada marca, e sim ao seu simples uso, como destacamos a seguir:

Para se reclamar o direito de precedência com base no uso anterior, o interessado deverá demonstrar que já utilizava, de boa-fé, marca idêntica ou semelhante, há, pelo menos seis meses da data do período de registro no Brasil ou da prioridade. Desde que reúna os pressupostos, o utente da marca poderá invocar o uso anterior da marca em face de pedido de registro perante o INPI. ${ }^{6}$

Além do uso há pelo menos 6 meses, o parágrafo Io exige que a utilização da marca ocorra no Brasil e em seu parágrafo $2^{\mathrm{o}}$ destaca de que forma o direito pode ser cedido a terceiros. A cessão deve ser feita de forma concomitante com o negócio da empresa, desde que haja relação com a marca.

\section{QUESTÃO CONSTITUCIONAL}

A proteção marcaria pode ser observada no art.5, inciso XXIX da nossa constituição, in verbis:

XXIX - a lei assegurará (...) proteção à propriedade das marcas, aos nomes de empresas e a outros signos distintivos, tendo em vista o interesse social e o desenvolvimento tecnológico e econômico do País.

\footnotetext{
${ }^{5}$ Ibidem. p.5.

${ }^{6}$ MOREIRA, Dannemann, Siemsen, Bigler \& Ipanema. Comentários à Lei da Propriedade Industrial e Correlatos. Renovar. 2001.p.274.
} 
A proteção identificada na Constituição se refere aos signos marcários criados e utilizados em determinado ramo de atividade, e não apenas aqueles registrados no INPI. Pois uma marca, não deixa de ser marca pelo não registro, apenas não está envolta de exclusividade pela Autarquia.

Como aponta o ilustre Barbosa "exatamente como ocorre em relação às patentes, existe um direito constitucional à proteção das marcas, direito esse que nasce da criação do signo como marcário e sua vinculação a uma atividade. Assim, justifica-se a tutela do uso" (BARBOSA, 2005, p. 9).

\section{MOMENTO OPORTUNO PARA SE ARGUIR O DIREITO DE PRECEDÊNCIA}

A principal questão que ronda o direito de Precedência diz respeito ao momento oportuno para sua invocação. A lei não traz de forma clara o ponto, deixando espécie de lacuna, que tanto Doutrina, quanto a Jurisprudência visam preencher.

O parágrafo Io do art.I29 da LPI fala apenas sobre a pessoa de boa-fé que, na data da prioridade ou depósito, usava no Brasil, há pelo menos 6 meses, marca idêntica ou semelhante inserida no mercado, terá direito de precedência ao registro.

Destarte, qual seria o momento de invocar tal instituto?

A Doutrina majoritária, entende que o momento oportuno para se arguir o direito de Precedência seria até o momento da concessão do registro, ou seja, o direito só é legítimo antes de ser concedido a propriedade sobre a marca.

Dessa forma, o utente de boa-fé deve se manifestar durante o tramite administrativo do INPI, mais precisamente no momento da oposição ${ }^{7}$, instante onde o terceiro interessado pode se opor contra o registro pretendido.

Mais uma vez nas palavras de Barbosa ${ }^{8}$ :

Uma vez adquirido o registro da marca, de forma legal e obedecendo todas as etapas processuais, sem que neste curso haja nenhuma impugnação deste registro, não há como argüir o direito de precedência.

${ }_{17}^{7} 8$ da LPI: Protocolizado, o pedido será publicado para apresentação de oposição no prazo de 6o (sessenta) dias.

${ }^{8}$ BARBOSA, Denis Borges, op. cit., p. 19. 
O direito de precedência é ao registro. Uma vez o registro já concedido, este benefício, que é uma exceção ao sistema atributivo do atual Código de Propriedade Industrial - CPI e, por tanto, deve ser interpretado e utilizado de maneira restritiva, deixa de existir."

No entendimento doutrinário, a partir do momento em que for constituída a propriedade da marca não mais há o que se falar em direito de precedência.

A questão também tem forte ligação com o Princípio da Segurança Jurídica, que possui previsão no art. $5^{\circ}$, inciso XXXVI da $\operatorname{CRFB}^{9}$ c/c o art.2o da Lei $9.784 / 99^{\text {Io }}$. O referido princípio seria afetado pelo fato de que a decisão administrativa poderia ser revista a “qualquer momento" caso o direito de precedência pudesse ser invocado também a qualquer momento.

Nesse caso, o parágrafo I을 do art. I29, deixaria a posição de exceção e se encaminharia para a regra, isto é, o uso seria privilegiado em nosso ordenamento, o que não condiz com o sistema atributivo, que fora escolhido pelo legislador para administrar o sistema marcário.

Esse entendimento perdurou durante muito tempo em nossos tribunais, como pode ser visto no julgado abaixo:

\section{APELAÇÃO - PROPRIEDADE INDUSTRIAL - PEDIDO DE NULIDADE DE MARCA - ARGUIÇÃO DE COLIDÊNCIA - NOME COMERCIAL - DIREITO DE PRECEDÊNCIA - RECURSO IMPROVIDO}

I - Ação proposta para anular o registro da marca "Super Campeão" com base em violação aos artigos 129, § Io e 124, incisos V e XXIII, da Lei 9.279/96.

II - O fato de as empresas se encontrarem constituídas em estado diferentes da federação, sem prova de extensão para os estados de uma da outra, afasta, de início, qualquer possibilidade de incidência do artigo I24, $\mathrm{V}$ da LPI, nos termos da jurisprudência já pacificada por esta Colenda Corte e pelo STJ.

III - Não prosperando, ainda, a arguição de direito de precedência, por não ter sido invocado em sede administrativa, durante os procedimentos de concessão das marcas da ré, com depósitos efetuados nos anos de 1999 e 2001 e expedição de títulos nos anos de 2006 e 2008.

IV - Apelação improvida (grifo nosso).

(TRF2. I ${ }^{\text {a }}$ Turma Especializada. Processo: ooo6543-98.2010.4.02.5101 Desembargador MESSOD AZULAY NETO. 26/05/2015)”.

\footnotetext{
${ }^{9}$ XXXVI - a lei não prejudicará o direito adquirido, o ato jurídico perfeito e a coisa julgada.

${ }^{10}$ Art.2 - A Administração Pública obedecerá, dentre outros, aos princípios da legalidade, finalidade, motivação, razoabilidade, proporcionalidade, moralidade, ampla defesa, contraditório, segurança jurídica, interesse público e eficiência.
} 
No julgado em destaque o Desembargador Federal MESSOD AZULAY NETO, nega a arguição de direito de precedência, por não ter sido invocado em sede administrativa, durante o período de concessão de registro. Em seu relatório o mesmo apontado o prazo certo delimitado para atuação da parte interessada no direito de precedência, vejamos:

Em que pesem as alegações da autora de "uso de fato" da expressão a título de marca, desde 1984 - na verdade, só tomou a iniciativa para registrá-lo muito depois da ré, em 2004, quando efetuou os depósitos de suas marcas, que acabaram sendo indeferidas, não se preocupando em impugnar os procedimentos de análise dos títulos da ré, em curso na mesma época, abrindo mão da faculdade conferida na lei, que, sabe-se, tem prazo certo delimitado pela atuação da própria parte.

O mesmo entendimento pode ser observado em outros julgados, como o apontado abaixo:

PROPRIEDADE INDUSTRIAL. APELAÇÃO. *SORVETE SEM NOME-. SISTEMA ATRIBUTIVO. USO. AUSÊNCIA DE PROVA E DE OPOSIÇÃO TEMPESTIVA AO REGISTRO EM NOME DE TERCEIRO. EXPRESSÃO DOTADA DE CARÁTER CRIATIVO E DISTINTIVIDADE. CESSÃO DA MARCA. POSSIBILIDADE.

I - No sistema atributivo, adotado pela Lei no 9.279/96, direito marcário, informado pelo sistema atributivo, o pré-utente tem direito de precedência ao registro de sua marca, se o exercer antes do ato administrativo concessivo a terceiro de boa-fé. Inteligência do art. 129, caput e § Io da Lei 9.279/96.

2 - A expressão "SEM NOME"-, dotada de caráter criativo e cunho distintivo suficiente, não se insere nas proibições do art. 124 da LPI, sobretudo porquanto não mantém relação direta com o produto ou serviço assinalado, podendo assinalar quaisquer outros produtos ou serviços e manter sua distintividade.

3- O titular do direito, protegido pelo registro marcário válido, adquirido nos termos do artigo 129 da LPI, pode exercê-lo de maneira que melhor lhe aprouver, inclusive com a cessão da marca, ato legal e facultativo ao seu titular, podendo ser negociada com terceiro, que, porém, deve comercializar o produto identificado com a expressão registrada como marca no INPI.

\section{4 - Apelação improvida}

(TRF-2 ${ }^{\text {a }}$ Região, Segunda Turma Especializada, Apelação Cível 201051018035544, AC 537972, Rel. Juíza Federal Convocada Márcia Maria Nunes de Barros, E-DJF2R de 18/o6/2012)”.

Como pode ser visualizado no julgado supracitado, o julgador aponta o momento ideal onde o pré-utente deve se manifestar: "o pré-utente tem direito de precedência ao registro de sua marca, se o exercer antes do ato administrativo concessivo a terceiro de boa-fé. Inteligência do art. 129, caput e § I음 Lei 9.279/96”. 
No que tange o posicionamento do INPI, o mesmo corrobora com o entendimento de que a oposição a ferramenta/momento ideal para invocar o direito de precedência, como pode ser observado abaixo:

Assim, a pessoa que, de boa-fé, usava no país, há pelo menos 6 (seis) meses, marca idêntica ou semelhante, para fins idênticos ou semelhantes, pode reivindicar o direito de precedência ao registro, devendo, para tanto:

a) Fundamentar sua reivindicação, exclusivamente em sede de oposição ao pedido de registro formulado por terceiros, instruindo-a de provas suficientes para caracterizar o uso no país, na conformidade do disposto no $\S$ Iํ do art. I29 da LPI;

b) Fazer prova do depósito do pedido de registro da marca, nos termos da LPI". ${ }^{\prime \prime}$

A autarquia não deixa dúvidas sobre a questão quando afirma que o interessado deve fundamentar sua reivindicação exclusivamente em sede de oposição. Ainda informa o que ocorre no caso de dois interessados no signo comprovarem o uso há pelo menos 6 meses antes da data do depósito e ou prioridade reivindicada, vejamos:

Se ambas as partes comprovarem o pré-uso do sinal marcário requerido, há pelo menos 6 (seis) meses antes da data do depósito e ou prioridade reivindicada, o direito sobre o registro da marca pertencerá àquele que primeiro depositar o pedido junto ao INPI, independente de quem faz uso há mais tempo".

O entendimento da instituição se dá por conta da expressão "precedência ao registro" observado no parágrafo Io do art.I29 da LPI. Através dessa leitura, a precedência é voltada ao registro e não a marca em si. Isso significa que o direito se extingue a partir do momento em que a marca é concedida.

\section{NOVO ENTENDIMENTO}

Porém, como se verá adiante o entendimento judicial atual se encontra na contramão dos fundamentos apresentados acima. O Superior Tribunal de Justiça, em recente decisão, entendeu que o direito de precedência pode ser utilizado para anular marca concedida pelo INPI, não sendo necessária a impugnação administrativa, nos termos da oposição.

Vejamos abaixo a Ementa do caso em questão:

\footnotetext{
${ }^{\text {II }}$ Manual de Marcas do INPI. p. 209.
} 
RECURSO ESPECIAL. AÇÃO ANULATÓRIA DE REGISTRO. MARCA. DIREITO DE PRECEDÊNCIA. EMBARGOS DE DECLARAÇÃO. OMISSÃO, CONTRADIÇÃO OU OBSCURIDADE. NÃO INDICAÇÃO. SÚMULA

284/STF. HARMONIA ENTRE O ACÓRDÃO RECORRIDO E A JURISPRUDÊNCIA DO STJ. PREQUESTIONAMENTO. AUSÊNCIA. SÚMULA 2II/STJ.

I- Ação distribuída em 8/8/20Ir. Recurso especial interposto em $17 / 7 / 2013$ e atribuído à Relatora em 25/8/2016.

2- Controvérsia que se cinge em definir se o registro da marca PADRÃO GRAFIA deve ou não ser anulado em virtude do direito de precedência alegado pela recorrida.

3- A ausência de expressa indicação de obscuridade, omissão ou contradição nas razões recursais enseja o não conhecimento do recurso especial.

4- O capítulo do acórdão recorrido que adota orientação firmada pela jurisprudência do STJ não merece reforma.

5- Não havendo manifestação do Tribunal de origem acerca de dispositivos legais indicados como violados, não obstante a interposição de embargos de declaração, a irresignação não pode ser conhecida.

6- É possível o reconhecimento judicial da nulidade do registro de marca com fundamento em direito de precedência (art. 129, § I으, da Lei 9.279/1996).

7- A Lei de Propriedade Industrial protege expressamente aquele que vinha utilizando regularmente marca objeto de depósito efetuado por terceiro, garantindo-lhe, desde que observados certos requisitos, o direito de precedência de registro.

8- Hipótese em que os juízos de origem - soberanos no exame do acervo probatório concluíram que a recorrida, de boa-fé, fazia uso de marca designativa de produto

idêntico ou semelhante, há mais de seis meses antes do pedido de registro formulado pela interessada.

\section{RECURSO ESPECIAL NÃO PROVIDO}

(STJ. 3 ${ }^{\text {a }}$ Turma. RECURSO ESPECIAL No 1.464 .975 - PR. Ministra Nancy Andrighi. OI/12/2016).

A empresa Padrão Grafia Industrial e Comercial LTDA moveu ação anulatória de ato administrativo do INPI que concedeu registro da marca PADRÃO GRAFIA para a empresa SERIPRINT INDÚSTRIA E COMÉRCIO DE ETIQUETAS LTDA.

Em suas alegações a requerente afirmou que embora tivesse requerido o registro para a mesma marca em data posterior, já utilizava o signo há pelo menos 6 meses da data do depósito do terceiro e por essa razão, tinha o direito de precedência garantido.

Em seu relatório a Ministra Nancy Andrighi deixou claro que o STJ possui entendimento firmado no sentido de que é plenamente viável a decretação de nulidade através do direito de precedência por via judicial. 
$\mathrm{O}$ argumento da Ministra se baseia no Princípio Garantidor do Acesso a Justiça, previsto no art.5 inciso XXXV da Constituição Federal Brasileira ${ }^{\mathrm{I} 2}$. Nesse diapasão, uma violação de direito individual não pode ser afastada do poder judiciário, porém precisamos questionar, a partir do momento em que a marca está registrada, o direito de precedência ainda vigora?

Pelo entendimento do STJ, sim. Não restando dúvidas sobre a possibilidade de arguir o direito de precedência em sede judicial. A Justiça Federal, inclusive, já tem se manifestado de acordo com o entendimento da Corte Superior, vejamos:

O TRF da $2^{\underline{a}}$ Região vinha adotando o entendimento de que tal faculdade deveria ser exercida na primeira oportunidade, ou seja, dentro do prazo de oposição previsto no art.158 da LPI (AC n. - $^{2010.51 .01 .810536-4, ~ R e l a t o r ~ D e s . ~ F e d . ~ M E S S O D ~ A Z U L A Y ~}$ NETO, j. 08/o4/2014 e AC n.o oo1956o- 36.2012.4.02.5101, Relator ANTONIO IVAN ATHIÉ, j. 09/o6/2016), após o que estaria consolidado o direito de propriedade em favor do titularız e não mais seria cabível a invocação de direito de precedência por via administrativa ou judicial. Entretanto, em recente julgamento da $3^{\underline{a}}$ Turma do STJi4, da relatoria da Ex.ma Ministra NANCY ANDRIGHI, foi firmado entendimento contrário, em acórdão cujo teor traz a seguinte ementa:

$[\ldots]$

Adotando o entendimento exposto no acórdão do STJ, deve-se entender que a invocação do direito de precedência com base no parágrafo único do art.I29 da LPI pode ser feita tanto na esfera administrativa quanto na judicial - mas desde que cumpridos, em qualquer caso, os prazos legais pertinentes.

(Justiça Federal da $2^{\underline{a}}$ Região. $13^{\underline{a}}$ Vara Federal do Rio de Janeiro. Processo: or7131619.2017.4.02.5101. Juiza Federal MARCIA MARIA NUNES DE BARROS. 19/12/2018)”.

A Iㄴ turma especializada, decidiu caso recente, tendo como base a decisão referida do STJ. Embora, no caso concreto, o interessado não tenha comprovado o uso de boa-fé, a possibilidade de invocação do direito de precedência foi conferida em sede judicial, ainda que não tenha sido requerido em oposição administrativa:

APELAÇÃO. PROPRIEDADE INDUSTRIAL. ALEGADO DIREITO DE PRECEDÊNCIA À MARCA “TRADIÇÃO”. NÃO VERIFICADO. POSSIBILIDADE DE INVOCAÇÃO DO DIREITO DE PRECEDÊNCIA EM SEDE JUDICIAL, MESMO QUE NÃO TENHA SIDO ALEGADO EM OPOSIÇÃO ADMINISTRATIVA. ENTENDIMENTO DO STJ. NA PRÁTICA, CONTUDO, NÃO COMPROVAR O USO EFETIVO E DE BOA-FÉ DA MARCA “TRADIÇÃO” PARA IDENTIFICAR OS SERVIÇOS DE ADMINISTRAÇÃO DE CONSÓRCIO NOS SEIS MESES QUE PRECEDERAM O DEPÓSITO DA MARCA “TRADIÇÃO” IMPUGNADA,

\footnotetext{
${ }^{\mathrm{I}} \mathrm{XXV}$ - a lei não excluirá da apreciação do Poder Judiciário lesão ou ameaça a direito.
} 
OCORRIDO EM 08.05.200I. IMPOSSOBILIDADE DE CONVIVÊNCIA ENTRE AS MARCAS. IMBRICAMENTO MERCADOLÓGICO. APELAÇÃO A QUE SE NEGA PROVIMENTO.

I - A apelante busca o deferimento dos pedidos de registro 903.956.438, 903.956.896, 903.957.051 e 905.019.202 para os respectivos sinais "TRADIÇÃ̂", "TRADIÇÃO CONSÓRCIO NACIONAL", "TRADIÇÃO CONSÓRCIO MOBILIÁRIO” e "T TRADIÇÃO CONSÓRCIO NACIONAL", depositados em 201 e 2012. Atualmente, o exame de tais pedidos encontra-se sobrestado porque o INPI ainda está analisando o requerimento de registro 823.233.014 para a marca mista “TRADIÇÃO, da apelada (TRADIÇÃO ADMINISTRAÇÃO E CORRETAGEM DE SEGUROS LTDAME.) e que fora depositado anteriormente, em 08.05.20or.

II - Para tanto, a apelante desenvolveu duas linhas de raciocínio, uma principal, pelo direito de precedência que teria à marca "TRADIÇÃO”, e outra em caráter eventual, pela possibilidade de convivência pacífica entre as marcas das partes.

III - O Superior Tribunal de Justiça firmou entendimento no sentido que o direito de precedência pode ser invocado pela primeira vez em sede judicial, sem que tenha sido alegado anteriormente em oposição administrativa. (Cf. REsp 1.464.975/PR. Rel. Ministra Nancy Andrighi, DJe 14.12.2016).

IV - A documentação juntada pela apelante é incapaz de comprovar o uso efetivo e de boa-fé da marca "TRADIÇÃO" para identificar os serviços de administração de consórcio nos seis meses que precederam o depósito da marca "TRADIÇÃO" impugnada, ocorrido em o8.05.2001.

$\mathrm{V}$ - Nesse sentido, as únicas duas certidões de protestos de títulos trazidas aos autos (fls. 378/379) apenas informam não constar protesto em nome da apelante, sem indicar qualquer serviço prestado, e muito menos a identificação de tais serviços pelo sinal “TRADIÇÃO”. Igualmente, os dois balancetes patrimoniais juntados (fls. 38o/38I) apenas revelam a situação contábil da apelante em 1999, sem retratar, contudo, a marca "TRADIÇÃO" sendo utilizada efetivamente no segmento investigado.

VI - De se notar, ainda, que a comprovação do uso deve se dar em escala compatível com a pretensão de quem o invoca. Assim, ainda que retratassem o uso da marca tradição pontualmente, as duas certidões de protesto e os dois balancetes seriam insuficientes para amparar as assertivas constantes na petição inicial de que a ora apelante seria "tradicionalmente conhecida em seu ramo de atividade" e constituiria "referência no mercado de consórcio".

VII - Impossibilidade de convivência pacífica entre as marcas. Há verdadeiro imbricamento mercadológico entre os segmentos em exame, na medida em que não raro a aquisição de um produto por consórcio normalmente é acompanhada da oferta de seguro para o caso de inadimplemento.

VIII - Apelação a que se nega provimento (grifo nosso).

(TRF2. I ${ }^{\mathrm{a}}$ Turma Especializada. Processo: 0052395-38.2016.4.02.5101. Desembargadora

Federal SIMONE SCHREIBER. 03/09/2018).

Reafirma-se, dessa forma, a possibilidade de alegação do direito de precedência pelas vias judiciais, ainda que não requerido em sede administrativa. No voto da Excelentíssima 
Desembargadora Federal SIMONE SCHREIBER, a mesma afirma a mudança de entendimento do nosso Superior Tribunal, conforme explicado nesse trabalho, vejamos a passagem citada:

Em se tratando de registro de marcas, vige no ordenamento jurídico brasileiro sistema predominantemente atributivo, em que a titularidade de uma marca é adquirida pelo seu registro no INPI. Esse modelo se contrapõe ao sistema declaratório, não adotado no Brasil, por meio do qual a titularidade de uma marca é adquirida pelo uso e no âmbito do qual o registro possuiria efeitos puramente declaratórios.

Contudo, a legislação marcária admite algumas exceções ao sistema atributivo, como na hipótese do direito de precedência. Nesse caso, o terceiro de boa-fé que, na data da prioridade ou depósito, usava no País, há pelo menos 6 (seis) meses, marca idêntica ou semelhante, para distinguir ou certificar produto ou serviço idêntico, semelhante ou afim, terá direito de precedência ao registro.

(...)

Apesar de a LPI não prever a forma e o prazo para o exercício do direito de precedência, a jurisprudência deste Tribunal Regional Federal sempre foi pacífica no sentido de que o direito de precedência constitui exceção à regra geral e, como tal, deve ser interpretado restritivamente, podendo ser arguido apenas até a expedição do registro de marca, durante o prazo para oferecimento de oposição administrativa.

CONTUDO, COMO CONSIGNADO PELA SENTENÇA, EM RECENTE JULGAMENTO, O SUPERIOR TRIBUNAL DE JUSTIÇA FIRMOU ENTENDIMENTO DIVERSO, NO SENTIDO QUE O DIREITO DE PRECEDÊNCIA PODE SER INVOCADO PELA PRIMEIRA VEZ EM SEDE JUDICIAL, SEM QUE TENHA SIDO ALEGADO ANTERIORMENTE EM OPOSIÇÃO ADMINISTRATIVA.

CONSIDERANDO A ALTERAÇÃO JURISPRUDENCIAL PROMOVIDA PELO SUPERIOR TRIBUNAL DE JUSTIÇA, PASSO A APLICÁ-LA NO ÂMBITO DESTA CORTE REGIONAL. ASSIM, NÃO HÁ QUALQUER IMPEDIMENTO AO EXAME DA TESE RELATIVA AO DIREITO DE PRECEDÊNCIA (GRIFO NOSSO).

(TRF2. I ${ }^{\mathrm{a}}$ Turma Especializada. Processo: 0052395-38.2016.4.02.5101. Desembargadora Federal SIMONE SCHREIBER. 03/09/2018)"

\section{CONSIDERAÇÕES FINAIS}

O direito de precedência como exposto no presente artigo de forma detalhada, é exceção ao sistema atributivo adotado no Brasil.

Dessa maneira, pelas escolhas feitas pelo legislador quando da criação da Lei de Propriedade Industrial, tudo leva a crer que o parágrafo Io do art.129 deve ser aplicado de 
forma restritiva, cabendo assim a invocação do mesmo, apenas na fase de tramitação administrativo do processo de registro marcário.

Entretanto, o posicionamento adotado pelo Superior Tribunal de Justiça, dilata o entendimento do referido dispositivo, permitindo assim, sua evocação na esfera judicial.

Em nosso entendimento, a posição adotada pelo STJ eleva o nível de importância do "uso da marca", não sendo compatível com o sistema adotado pela Federação. Não temos aqui o objetivo de discutir a legitimidade do uso anterior como "prioridade" para a concessão do registro.

A incompatibilidade referida se dá apenas pelo sistema atributivo presente na Lei de Propriedade Industrial. Quando a corte brasileira passa a entender que o uso anterior pode à qualquer momento ser invocado e, dessa forma, cancelar registro concedido de forma legitima, o dispositivo que fora criado como exceção passa a ser regra.

O utente que provar o uso da marca, nas especificações apontadas no artigo I29 da LPI, terá o direito de anular o registro alcançado de forma legítima. Tal conceito fere diretamente o Princípio da Segurança Jurídica previsto no art.2o da Lei $9.784 / 99^{13}$ e no art. $5^{\mathrm{o}}$ da Constituição Federal Brasileira em seu inciso XXXVI ${ }^{14}$.

A título de exemplo, o empresário que visa abrir estabelecimento e trabalhar sua marca, ainda que consiga o registro frente a Autarquia Federal, jamais terá a tranquilidade ,que o registro marcário deveria lhe conceder, para investir no sinal distintivo, uma vez que agora, ainda que seu signo não tenha sofrido impugnação durante o tramite administrativo, poderá sofrer impugnação com base no direito de precedência pela via judicial.

Nesse diapasão, o sistema atributivo que prioriza o registro ao uso, passa a entender que o uso anterior pode derrubar o registro a qualquer tempo, dentro do prazo judicial previsto logicamente, invertendo as prioridades estabelecidas pelo sistema.

${ }^{13}$ A Administração Pública obedecerá, dentre outros, aos princípios da legalidade, finalidade, motivação, razoabilidade, proporcionalidade, moralidade, ampla defesa, contraditório, segurança jurídica, interesse público e eficiência.

${ }^{14}$ XXXVI - a lei não prejudicará o direito adquirido, o ato jurídico perfeito e a coisa julgada. 


\section{REFERÊNCIAS}

BARBOSA, Denis Borges. Direito de Precedência ao Registro de Marcas. 2005.

BRASIL, Constituição da República Federativa Do Brasil De 1988.

BRASIL, LEI № 9.279, DE I4 DE MAIO DE 1996. Regula direitos e obrigações relativos à propriedade industrial.

JUSTIÇA FEDERAL DA 2 ${ }^{\text {a }}$ REGIÃO. 13 ${ }^{\text {a }}$ Vara Federal do Rio de Janeiro. Processo: or7ı31619.2017.4.02.5101. Juíza Federal MARCIA MARIA NUNES DE BARROS. 19/12/2018

Manual de Marcas do INPI.

MOREIRA, Dannemann, Siemsen, Bigler \& Ipanema. Comentários à Lei da Propriedade Industrial e Correlatos. Renovar. 200I.

STJ. 3 $3^{\text {a }}$ Turma. RECURSO ESPECIAL № $\mathbf{1 . 4 6 4 . 9 7 5 ~ - ~ P R . ~ M i n i s t r a ~ N a n c y ~ A n d r i g h i . ~}$ OI/I2/2016.

TRF2. I ${ }^{\text {a }}$ Turma Especializada. Processo: 0006543-98.2010.4.02.5101 Desembargador MESSOD AZULAY NETO. 26/05/2015.

TRF2. I ${ }^{-}$Turma Especializada. Processo: 0052395-38.2016.4.02.5101. Desembargadora Federal SIMONE SCHREIBER. 03/o9/2018.

TRF2. I ${ }^{\text {a }}$ Turma Especializada. Processo: 0052395-38.2016.4.02.5101. Desembargadora Federal SIMONE SCHREIBER. 03/o9/2018.

TRF-2 a Região, Segunda Turma Especializada, Apelação Cível 201051018035544, AC 537972, Rel. Juíza Federal Convocada Márcia Maria Nunes de Barros, E-DJF2R de 18/o6/2012. 